\title{
Prediction model for peak expiratory flow among children in Kocaeli, Turkey
}

Gundogdu $\mathrm{Z}^{\mathrm{a}}$, Gundogdu $\mathrm{O}^{\mathrm{b}}$

${ }^{a}$ Kocaeli Metropolitan Municipality Maternity and Children Hospital, Kocaeli,, Turkey

${ }^{b}$ Royal Surrey County Hospital, Guildford, UK.

ABSTRACT

Objective: To evaluate Peak Expiratory Flow (PEF) values in Turkish children between the ages 6 and 14 years old according to height, gender and age. Methods: Data was obtained from public health screening days in primary care practice on 1439 children. Peak expiratory flow (PEF) was measured for each child with a Mini Wright Peak Flow Meter. The study was assessed to find a correlation between heights, age and PEF values in children. Results: In our study, PEF values increased significantly with age and height in both genders. According to our results, the equation for prediction of PEF was calculated for girls as $(7.37 \times$ age [years])+ $(3.02 \times$ height $[\mathrm{cm}])-222.1(p<.001, r=0.83)$ and for boys $(7.92 \times$ age [years] $)+(3.13 \times$ height $[\mathrm{cm}])-230.9$ $(p<.001, r=0.83)$. Conclusions: The PEF values are statistically significant associated with age and height for girls and boys. The prediction equations specifically developed for children in Kocaeli can be used in clinical practice and these equations may help clinicians to better characterize individual or population airway responsiveness.

KEYWORDS: Peak expiratory flow, Children, Gender, Height, Age

\section{INTRODUCTION}

The rate of pulmonary diseases in childhood, especially bronchial asthma, is increasing in the world. ${ }^{1}$ In the evaluation and management of bronchial asthma, simple instruments for measurements of the peak expiratory flow (PEF) are needed. ${ }^{2}$

Peak Expiratory Flow (PEF) is an important parameter in the management of bronchial asthma and it is an easy-to-measure test, which can be performed with a relatively simple, cheap and portable instrument for a quick evaluation. PEF is an important measure in the management of asthma, just as blood pressure measurement is for hypertension or blood glucose for diabetes, and it provides a simple quantitative measure of the resistance and severity of airflow obstruction. The patient's measured personal best (the highest PEF) is recorded and should be used for comparison to reference values. ${ }^{3}$

Reversible and variable airflow limitation are measured by using a spirometer to measure (FEV1 and FVC) or a peak expiratory flow (PEF) meter in children over 5 years of age. ${ }^{4}$ The PEF meter is very popular in primary care and commonly applied as a quick screening method of assessing lung function in

Corresponding author:

Dr Zuhal Gundogdu

Kocaeli Metropolitan Municipality Maternity and

Children Hospital,

Kocaeli, 41028, Turkey

Email : z.gundo@gmail.com :z.gundo@yahoo.com the clinic or at the bedside. ${ }^{5}$ Several kinds of peak flow meters are available and the measurement technique used is similar for all of them. ${ }^{4,6}$

Pulmonary function variables are known to vary with age, sex, height, weight, race and geographic location. ${ }^{1}$ During the past 20 years, it has been recognised that, in addition to age, sex and height differences in PEF, there are lung function differences between subjects from different races such as reported for Hispanics, Orientals and Indians when compared with European, white North American children or Tunisian children. ${ }^{1,7}$

The aim of this study is to evaluate PEF values of healthy Turkish children in Kocaeli according to height, gender and age.

\section{MATERIALS AND METHOD}

This study has been carried out using secondary data gathered from children between the ages of six and fourteen years, who were brought in by parents during weekly public screening days at Kocaeli Metropolitan Municipality Maternity and Children's Hospital in Kocaeli, Turkey during the year 2002. The history of every child was taken by doctors. Children who had major disorders (cardiac, respiratory, renal or haematological disorders) were not considered in this study.

Heights and weights were measured for every child, with shoes off and wearing the least possible clothes. Height was measured by a stadiometer attached to the wall. Weight was obtained by standing on zeroed electronic scales. 
The same anthropometric equipment was used for each child. Weight measurements were in kilograms and height measurements in centimetres to the nearest millimetre. Age on the day of measurement was calculated in (decimal) years. Each child placed their feet on the base of the stadiometer and stood up with their back touching the vertical plate.

For PEF measurement, the child was asked to stand up and hold the peak flow meter without restricting movement of the marker. The doctor made sure that the marker was at the bottom of the scale for each measurement. The child took a deep breath, put the peak flow meter in his or her mouth, sealed his or her lips around the mouthpiece, and breathed out as hard and fast as possible, with the head in a neutral position, neither flexed nor extended. They were told repeatedly not to put their tongue into the mouthpiece. The marker was returned to zero after every measurement. To avoid the problem of variability due to different technicians and devices, all the tests were performed by one designated person using a Mini Wright Peak Flow Meter and (PEF) l/min was determined by a standard method. ${ }^{4}$

The results were evaluated to find a possible correlation between heights, age and PEF values in Turkish children in paediatric primary care. Statistical evaluation of the results was performed with the SPSS v14 computer program using simple multiple linear regression. All significance tests were based at the 0.05 level of significance.

\section{RESULTS}

1439 children with a mean age of $9.67 \pm 2.59$ years were enrolled in the present study, with a male/female ratio of $763 / 676$.

Mean and standard deviation (SD) of anthropometric and PEF values are shown in Table I. The mean age, height and weight were similar for girls and boys but it was found that PEF was significantly higher for boys than girls.

Table I. Mean age, height, weight, and PEF in girls and in boys.

(Mean; SD: standard deviation; PEF: peak expiratory flow (l/min), n: number)

\begin{tabular}{|c|c|c|c|c|}
\hline Gender & $\begin{array}{c}\text { Age (Years) } \\
(\text { Mean } \pm \text { SD) }\end{array}$ & $\begin{array}{l}\text { Height (cm) } \\
\text { (Mean } \pm \text { SD) }\end{array}$ & $\begin{array}{l}\text { Weight (kg) } \\
\text { (Mean } \pm \text { SD) }\end{array}$ & $\begin{array}{c}\mathrm{PEF}(\mathrm{l} / \mathrm{min}) \\
(\text { Mean } \pm \mathrm{SD})\end{array}$ \\
\hline Girls $(n=676)$ & $9.64 \pm 2.55$ & $133.27 \pm 15.90$ & $32.57 \pm 12.16$ & $252.61 \pm 78.11$ \\
\hline Boys $(n=763)$ & $9.69 \pm 2.63$ & $134.17 \pm 16.52$ & $32.72 \pm 11.80$ & $266.21 \pm 85.39$ \\
\hline
\end{tabular}

Mean height is shown separately for girls and boys aged 6-14 years in Table II. The mean PEF values for each age and gender are also shown. It shows that as height increased, PEF values also increased with age in both girls and boys.

Table II. Mean height and PEF according to age and gender.

\begin{tabular}{ccccccc|}
$\begin{array}{c}\text { Age } \\
\text { (years) }\end{array}$ & \multicolumn{2}{c}{ Number, $\mathbf{n}$} & \multicolumn{2}{c}{$\begin{array}{c}\text { Height }(\mathrm{cm}) \\
\text { (Mean } \pm \text { SD) }\end{array}$} & \multicolumn{2}{c|}{$\begin{array}{c}\text { PEF }(\mathrm{l} / \mathrm{min}) \\
\text { (Mean } \pm \text { SD) }\end{array}$} \\
\hline & Girts & Boys & Girls & Boys & Girls & Boys \\
\hline 6 & 71 & 95 & $114.66 \pm 5.16$ & $114.81 \pm 5.82$ & $175.45 \pm 30.35$ & $184.41 \pm 30.87$ \\
\hline 7 & 113 & 123 & $118.73 \pm 5.83$ & $118.98 \pm 6.11$ & $188.84 \pm 33.13$ & $195.69 \pm 37.45$ \\
\hline 8 & 81 & 82 & $123.98 \pm 8.39$ & $124.07 \pm 6.32$ & $212.34 \pm 44.89$ & $217.31 \pm 43.17$ \\
\hline 9 & 93 & 85 & $127.72 \pm 7.30$ & $129.81 \pm 6.80$ & $221.93 \pm 44.06$ & $245.29 \pm 48.04$ \\
\hline 10 & 73 & 80 & $134.02 \pm 7.20$ & $134.22 \pm 6.50$ & $264.52 \pm 51.64$ & $270.87 \pm 49.84$ \\
\hline 11 & 44 & 71 & $140.70 \pm 7.89$ & $140.94 \pm 7.16$ & $273.86 \pm 43.30$ & $288.59 \pm 49.14$ \\
\hline 12 & 72 & 67 & $148.00 \pm 7.11$ & $144.70 \pm 7.37$ & $312.63 \pm 49.70$ & $309.85 \pm 54.34$ \\
\hline 13 & 67 & 80 & $153.02 \pm 7.48$ & $154.33 \pm 8.14$ & $347.16 \pm 56.05$ & $357.12 \pm 69.04$ \\
\hline 14 & 62 & 80 & $157.00 \pm 7.37$ & $160.45 \pm 8.06$ & $354.83 \pm 69.93$ & $392.12 \pm 74.57$ \\
\hline
\end{tabular}

Mean; SD: standard deviation; PEF: peak expiratory flow (l/min), N: number) 
PEF values were also found to be highly correlated with the standing height in both girls and boys as shown in Figures $1 \mathrm{a}$ and $1 \mathrm{~b}$.

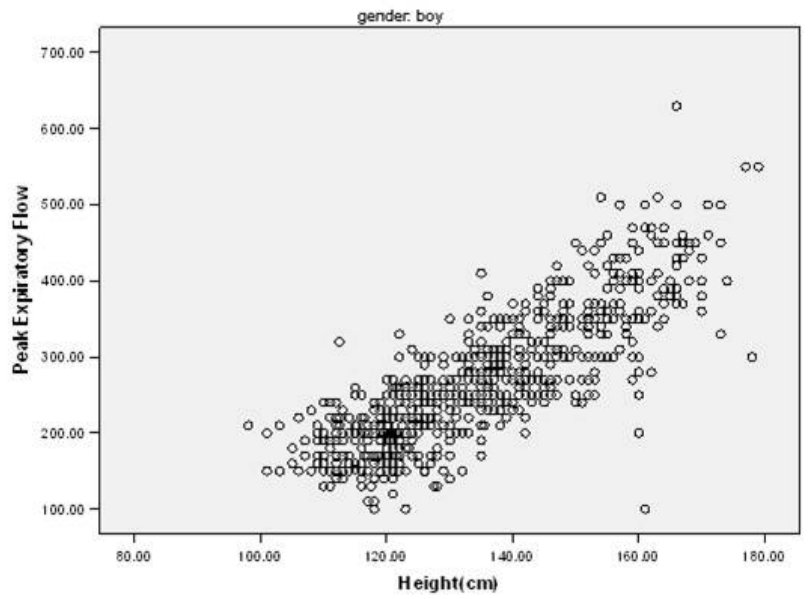

A

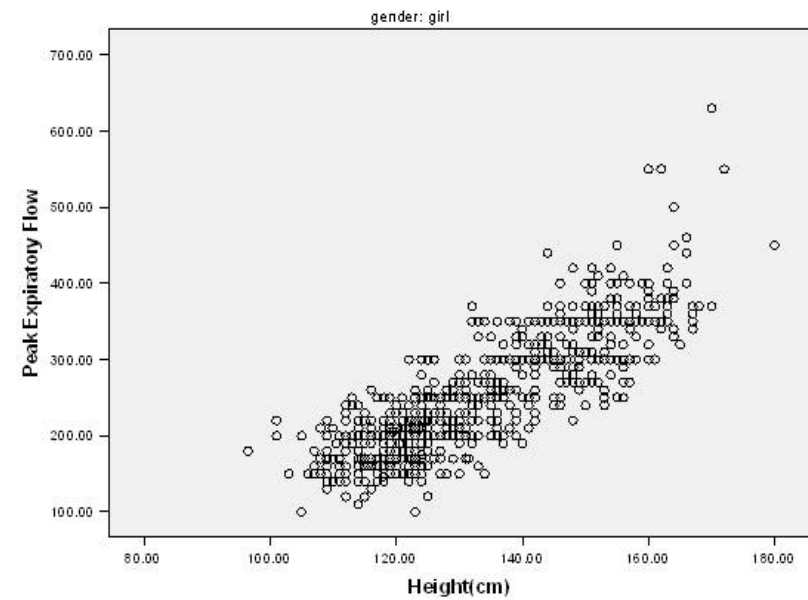

B

Figure 1. PEF (l/min) values plotted against standing height in $(A)$ healthy boys and $(B)$ girls.

The regression coefficients for the equations using height and age as the dependent variables are shown for the two genders separately in Table III. The choice of an appropriate regression model is made on the basis of variation of the dependent variable, the coefficient of determination, and a constant residual standard deviation over the range of ages. The PEF values for both genders are presented with standing height and age as the dependent variable. Our data show a significant increase in lung function with standing height in both genders. There was a statistically significant increase in PEF $(P<.001)$ with increasing height. PEF values increased significantly from age 6 to 14 for both genders, as shown in Table III. The PEF values are statistically significant associated with age and height for girls and boys. These estimates are similar for girls and boys.

Table III. Regression equations predicted by standing height and age in healthy Turkish children.

\begin{tabular}{|c|c|c|c|c|c|c|}
\hline $\begin{array}{l}\text { Dependent } \\
\text { variable }\end{array}$ & & $\begin{array}{c}\mathrm{B}_{\mathbf{0}} \\
\text { Constant }\end{array}$ & $\begin{array}{c}B_{1} \\
\text { age }\end{array}$ & $\begin{array}{c}B_{2} \\
\text { height }\end{array}$ & p & $\mathrm{R}^{2}$ \\
\hline \multirow[t]{2}{*}{ PEF (L/min) } & Girls & -222.14 & 7.37 & 3.02 & $<.001$ & 0.704 \\
\hline & Boys & -230.95 & 7.92 & 3.13 & $<.001$ & 0.697 \\
\hline
\end{tabular}

PEF: Peak expiratory flow (l/min), R2: correlation coefficient, $p<0.001$ statistical significance, [B0: constant, B1: age coefficient, B2: height coefficient]

[Function: $\mathrm{PEF}=\mathrm{b} 0+\mathrm{b} 1 \mathrm{x}$ age $($ years $)+\mathrm{b} 2 \mathrm{x}$ height $(\mathrm{cm})$ ]

[Formula For girls: $(7.37 \times$ age [years] $)+(3.02 \times$ height $[\mathrm{cm}])-222.1(\mathrm{p}<.001, r=0.83)$

For boys $(7.92 \times$ age [years] $)+(3.13 \times$ height $[\mathrm{cm}])-230.9(\mathrm{p}<.001, \mathrm{r}=0.83)]$ 


\section{DISCUSSION}

The aim of this study is to establish and evaluate predictive equations of PEF measured for healthy children, whose history was taken and who were medically examined in primary medical care in Turkey.

Lung function is known to vary with ethnicity and it is therefore important to establish normative values relevant to the ethnic groups of the local population. Apart from genetic constitution, environmental factors affecting growth and development such as child health, nutritional status and air quality may change over a long period and therefore lung function values for a given ethnic community may also change over time. ${ }^{8}$

For example, it has been reported that black males have spirometric parameters that are $10-13 \%$ lower than white males of European descent. ${ }^{7}$ Some previous studies reported significantly lower lung volumes in healthy Asian people as compared for instance to the children in a European community. ${ }^{9}$

In our study, linear regression models were carried out by treating the two genders separately and including PEF as the dependent variable. Height and age were also included in the regression model. Our results show that PEF values increased significantly with age and height in both genders. Our results were similar to those described elsewhere. ${ }^{1,10,11}$

Polgar's reference values were proposed in children and adolescents, with the same values for males and females. ${ }^{12}$ More recently, in 1981, Knudson proposed different PEF values for children and adoles

cents and for males and females as cited in. ${ }^{13}$

Our results show PEF values are significantly higher in boys than girls. Although there were no significant differences between mean height for boys and girls, PEF values increased with age and height and were significantly higher in boys than girls in our study. A study of PEF in a Mexican population also found, higher values for males than females, as in this study. ${ }^{13}$

According to our results, the equation for prediction of PEF was calculated for girls as $(7.37 \times$ age [years] $)+$ $(3.02 \times$ height $[\mathrm{cm}])-222.1(\mathrm{p}<.001, \mathrm{r}=0.83)$ and for boys $(7.92 \times$ age [years] $)+(3.13 \times$ height $[\mathrm{cm}])-230.9$ $(\mathrm{p}<.001, \mathrm{r}=0.83)$ respectively.

PEF values were also compared with another Turkish study carried out in Istanbul, where PEF values were recorded using a Mini Wright peak flow meter and their results were slightly higher than ours. ${ }^{2}$ The slight difference in results might be due to different geographic locations and possible differences in environmental conditions and nutritional status.

The findings support the view that the differences seen in PEF between different populations as also reported in may be influenced by exogenous factors and it should be borne in mind that these influences themselves may be subject to change with time. ${ }^{1,7,8}$ On the other hand, according to our results, PEF values of Turkish children were similar to those of British and Danish children, but significant differences were noted from Mexican American, African-American and white American Children. ${ }^{14,15,16}$

\section{CONCLUSIONS}

PEF values in this study are statistically significant associated with age and height for girls and boys. These estimates are similar for both sexes. The high correlation coefficients in this relatively large sample suggest that these results can be considered to be reliable. Kocaeli is a cosmopolitan city and the prediction equations from this region could be used as a tool to calculate PEF values and the expected peak expiratory flow rates for Turkish children in the city. The use of other reference values derived for other population may not be appropriate as this might lead to errors in clinical evaluation and appropriate equations and trends should be developed and used in clinical practice. However, further studies are required to form more conclusive reference values for Turkish children possibly extended to include regional and ethnic differences. We conclude that our findings would serve as an important basis for preparing centile curves for PEF values for healthy Turkish children and may fill the deficiency in the reference values.

\section{REFERENCES}

1. Trabelsi Y, Ben Saad H, Tabka Z, et al. Spirometric Reference Values in Tunisian Children. Respiration 2004; 71:511-8

2. Öneș Ü, Somer A, Sapan N, et al. Peak Expiratory Flow Rates in Healthy Turkish Children Living in Istanbul, Turkey. Allergy Asthma Proc 2004; 25:313-20

3. Balasubramanian S, Ravikumar NR, Chakkarapani E, et al. Peak Expiratory Flow Rate in children-A ready reckoner. Indian J Pediatr 2002; 39: 104-6

4. A Pocket Guide for Physicians and Nurses (Updated 2005) based on the workshop report: global strategy for asthma management and prevention updated (2005). Updated from the NHLBI/WHO Workshop Report. NIH Publication No. 02-3659. Available at www.ginasthma.org.

5. Brand PLP, Roorda RJ. Usefulness of monitoring lung function in asthma. Arch Dis Child 2003; 88:1021-5

6. Peter DS, Felicity F. Is home monitoring of lung function worthwhile for children with asthma? Thorax 2001; 56:164-5

7. Radeos MS, Camargo CA. Predicted Peak Expiratory Flow: Differences Across Formulae in the Literature. Am J Emerg Med 2004; 22:516-21 
8. Mary SM, Karlberg EM, Karlberg JPE, et al. Function Reference Values in Chinese Children and Adolescents in Hong Kong I. Spirometric Values and Comparison with Other Populations. Am J Respir Crit Care Med 2000; 162:424-9

9. Boskabady MH, Keshmiri M, Banihashemi B, et al: Lung function values in healthy non-smoking urban adults in Iran. Respiration 2002; 69:320-6

10. Bazdawi M, Al-Riyami BM, Al-Rawas OA, et al. Normal spirometric reference values for Omani children and adolescents.

Respirology 2004; 9:387-91

11. Vijayan VK, Reetha AM, Kuppurao KV, et al. Pulmonary function in normal south Indian children aged 7 to 19 years. Indian J Chest Dis Allied Sci 2000; 42:147-56

12. Polgar G, Promadhat V. Pulmonary function testing in children. Philadelphia WB: Saunders Company, 1971:87-212.

13. Lara-Pérez EA. Peak Expiratory Flow at Sea Level. Int Pediatr 2001; 16:89-93

14. Godfrey S, Kamburoff PL, Nairn JR. Spirometry, lung volumes and airway resistance in normal children aged 5 to 18 years. Br J Dis Chest 1970; 64:15-24

15. Host A, Host AH, Ibsen T. Peak Expiratory Flow Rate in Healthy Children aged 6-17 years. Acta Paediatr 1994; 83:1255-7

16. Hsu KHK, Jenkins DE, Hsi BP, et al. Ventilatory functions of normal children and young adults-Mexican-American, White, and Black: II. Wright peak flowmeter. J Pediatr 1979; 95:192-96 
THE INTERNATIONAL MEDICAL JOURNAL

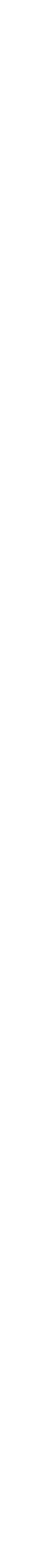

